\title{
PEMBELAJARAN DAN APLIKASI MAKNA INTERPERSONAL: TRANSAKSIONAL: PROPOSAL SEBAGAI PEMAHAMAN AKTIVITAS BERBAHASA STAF HOUSEKEEPING DAN FOOD AND BEVERAGE SERVICE DALAM MENGHADAPI PERMINTAAN DARI TAMU ASING
}

\section{(Pendekatan Linguistik Sistemik Fungsional)}

\author{
Oleh: \\ Vilya Lakstian Catra Mulia \\ Dosen di Institut Agama Islam Negeri Surakarta; \\ vilyalakstian@gmail.com
}

\begin{abstract}
Hotel staffs are obligated to have skills for handling guests' requests, especially for housekeeping (HK) and food and beverage (FB) divisions. The services are not only limited to which are done physically, but also in language issues. HK and FB, who are dominantly not English-educated background, have course, especially for encountering various requests from foreign guests. This article is composed by the writer from his experience as English instructor for those staffs. He teaches the English lesson purposed for the staffs so that they can identify there is a request from the guest and how to respond. The learning was done by using systemic functional linguistics approach, through modulated interrogative and inclination clauses, to reach the goal. Both showed exchanges toward goods and service. This learning has found a new way in language activity, so that the learners can internalize themselves towards language structures which have certain function with reasoned background relating to context.
\end{abstract}

Key Terms Definitions: housekeeping, food and beverage, guests, hotel, requests, English, systemic functional linguistics, interrogative, inclination, modulation

\section{PENDAHULUAN}

Sektor pariwisata dunia saat ini berkembang pesat. Hal ini didukung oleh dukungan dari setiap pemerintah untuk menjadikan pariwisata sebagai bagian dari pendapatan, sekaligus kebanggaan suatu negara. Hotel menjadi tempat yang tepat bagi wisatawan untuk menginap, sebelum melanjutkan perjalanan kembali. Oleh karena itu, pelayanan terhadap tamu hotel semakin ditingkatkan. Sebagai bentuk pelayanan, staf hotel harus siap untuk memperoleh kepuasan tamu. Bahasa Inggris menjadi bahasa asing yang harus dikuasai, karena posisinya saat ini yang masih menjadi lingua franca dunia. Dengan semangat pelayanan hotel dan dukungan pemerintah, diharapkan akan datang wisatawan dari seluruh dunia. 
Dengan latar belakang ini, staf hotel akan mendapatkan pelatihan atau kursus Bahasa Inggris. Tentu, agar mereka siap menghadapi tamu-tamu hotel dari luar negeri. Pembelajaran bahasa ditekankan pada beragam hal berkaitan dengan aktivitas berbahasa saat mereka bertugas di hotel. Oleh karena itu, Zwier dan Caplan (2007: 4) mengatakan bahwa pembelajaran bahasa untuk staf hotel harus membentuk event schemata, sehingga mereka dapat membayangkan gambaran apa saja yang diharapkan dari tamu hotel beserta bagaimana staf menghadapinya. Untuk membentuk skemata ini, pembelajaran bahasa memerlukan pemahaman konteks dari setiap peserta didik. Halliday (2004) memaparkan bagaimana bahasa melakukan fungsinya melalui tiga konteks, yaitu medan (field), pelibat (tenor), dan cara (mode). Dari konteks tersebut, terdapat tiga metafungsi yaitu ideasional, interpersonal, dan tekstual. Dalam pembelajaran ini, lebih cenderung ditekankan pada fungsi interpersonal, karena melibatkan penggunaan bahasa bersama dengan peran yang sedang dilakukan dengan orang lain. Peran yang terjadi adalah antara staf dengan tamu.

Salah satu hal yang akan ditemui saat berhadapan dengan tamu adalah saat menghadapi permintaan (request), khususnya bagi staf housekeeping atau HK (petugas pelayanan kamar hotel) dan food and beverage service atau FB (petugas pelayanan restoran). Permintaan tamu didominasi berupa barang dan jasa. Atas kewajibannya untuk melayani tamu, mereka harus bisa mengidentifikasi tuturan dari tamu yang menunjukkan bahwa tamu itu sedang meminta sesuatu, misalnya "Could you bring me extra towel?" atau "May I have more shampoo?". Contoh tersebut menunjukkan bahwa kedua klausa tersebut sedang mengekpresikan rangkaian unsur bahasa sehingga membentuk struktur bahasa tertentu. Mayoritas staf HK dan FB bukan dari latar belakang pendidikan Bahasa Inggris. Sehingga, mereka perlu untuk menginternalisasikan dirinya dengan berbagai ekspresi dari struktur bahasa untuk menjalankan fungsi meminta sesuatu oleh tamu.

Hedge (dalam Basturkmen, 2006: 35) mengatakan, terdapat suatu kebangkitan kembali untuk memperhatikan grammar sebagai kunci dalam pembelajaran bahasa. Pembelajaran bahasa dengan pendekatan Linguistik Sistemik Fungsional (LSF) sangat tepat untuk menunjukkan bagaimana suatu tuturan melalui grammar memiliki fungsi pertukaran. Pada konteks pelayanan hotel ini, pertukaran itu adalah barang dan jasa. Jenis pertukaran ini sejalan dengan peran mereka dalam bertugas, yaitu memberikan pelayanan. Dengan sifatnya yang fungsional, pendekatan ini akan membawa para staf tersebut dalam mengkaitkan partisipan dengan konteks situasi yang koheren dengan grammar. 


\section{METODE}

Penyajian artikel ini tidak dilakukan dengan data numerik, karena data yang dipakai berupa klausa dan leksis untuk proses pembelajaran materi request (permintaan). Artikel ini mendeskripsikan pengajaran materi tersebut dengan pendekatan LSF. Sehingga, artikel ini disajikan secara kualitatif deskriptif, karena pengumpulan dan analisis data bukan numerik (Blaxter et al, 1996: 60). Pendeskripsian data tersebut dilakukan karena memiliki makna (Sutopo, 2006: 40). Temuan berasal dari proses pembelajaran Bahasa Inggris untuk para staf HK dan FB yang dibimbing oleh penulis. Pembelajaran ini dilakukan untuk memberikan pemahaman terhadap materi request, sehingga merupakan studi kasus karena dibentuk dengan lingkungan (situasi belajar) dan konteks.

Partisipan yang terdapat dalam penelitian ini adalah staf HK dan FB dengan setting kelas Bahasa Inggris. Hubungan partisipan dan setting adalah untuk menciptakan kondisi dalam usaha memahami konteks percakapan tentang menghadapi permintaan tamu. Hal ini merupakan aplikasi dari tiga aspek lokasi penelitian, yaitu setting, partisipan, dan kejadian (Spradley, 1980). Dari lokasi penelitian, didapatkan data. Sudaryanto (1990: 1) mengatakan bahwa data adalah bahan penelitian. Data diambil dari aktifitas belajar Bahasa Inggris dengan klausa-klausa untuk bahan pengajaran. Khusus untuk penyajian artikel ini, fokus pada materi request. Pengumpulan data diperoleh dari observasi dimana penulis juga terlibat, yaitu sebagai instruktur. Observasi dilakukan di International Hospitality Center Surakarta, sebuah kampus pendidikan untuk staf hotel. Sutopo (2006: 57) menjelaskan bahwa sumber data adalah dari mana data diperoleh baik tempat, informan, kejadian, dokumen, situs, dan sebagainya. Penelitian ini menggunakan tempat, partisipan, dan kejadian. Ketiganya aspek itu tertuju pada kelas Bahasa Inggris beserta staf dengan aktivitas belajar untuk memahami materi.

Dengan penjelasan metode tersebut, penulis mendapatkan berbagai temuan. Temuan itu tersaji melalui bagaimana pembelajaran materi request diperkenalkan kepada staf dengan menggunakan struktur mood pada klausa interogatif termodulasi, dan inklinasi termodulasi untuk mengekspresikan makna transaksi proposal.

\section{PEMBAHASAN}

Hubungan yang dibentuk dalam konteks tujuan pembelajaran bahasa ini adalah mengaplikasikan peran staf dan tamu hotel. Pemahaman peran ini akan membuat para peserta didik, yaitu staf HK dan FB service menginternalisasikan posisi mereka dalam 
mengaplikasikan aktivitas berbahasa. Hubungan sosial ini di dalam LSF sebagai hubungan interpersonal.

Hubungan interpersonal akan berjalan baik dengan melakukan tuturan-tuturan dengan berbagai fungsinya bersama dengan sikap dan penilaian antar partisipannya (Halliday dan Hassan, 1985: 45). Fungsi tuturan yang menjadi topik dalam artikel ini adalah permintaan. Realisasinya, partisipan akan mengekspresikan fungsi tersebut dengan struktur bahasa. Struktur tersebut pada tataran klausa, LSF menyebutnya leksikogrammatika (lexicogrammar). Leksikogrammatika adalah rangkaian unsur bahasa yang terangkai dalam tata bahasa. Djatmika (2012: 33) menjelaskan bahwa leksikogrammatika merupakan katakata yang berada di dalam struktur grammatika.

Leksikogrammatika yang sejalan dengan interpersonal adalah struktur mood. Permintaan menunjukkan adanya pertukaran yang terjadi. Struktur mood menunjukkan pertukaran itu dengan melibatkan subjek dan finite.

Pembelajaran ini menggiring para staf untuk menuju pada konteks pelibat (tenor) dalam membentuk hubungan sosial (interpersonal) dengan menuturkan bahasa dengan fungsi pertukaran tertentu (melalui struktur mood).

Untuk memahami apakah tamu sedang meminta sesuatu adalah dengan mengidentikasi penggunaan lexical item. Eggins (2005: 58) menunjukkan tentang bagaimana penggunaan unsur leksikal tertentu sebagai bentuk koherensi terhadap konteks. Pada proses pembelajaran awal, para peserta menyebutkan leksis-leksis yang merujuk pada saat tamu meminta sesuatu. Beberapa leksis seperti clean, mop, wash, blanket, floor, dan toilet berhubungan dengan tugas HK. Sedangkan change, taste, salt, pepper, foods, dan soup berhubungan dengan FB.

Agar aplikasi berbahasa ini sejalan dengan konteks, berbagai leksis tersebut berkembang membentuk klausa. Maka, perlu untuk membuat para staf ini paham, yaitu dengan membentuk skemata. Skemata tersebut dapat dibantu dengan penyajian tabel, seperti yang tampak berikut ini. 


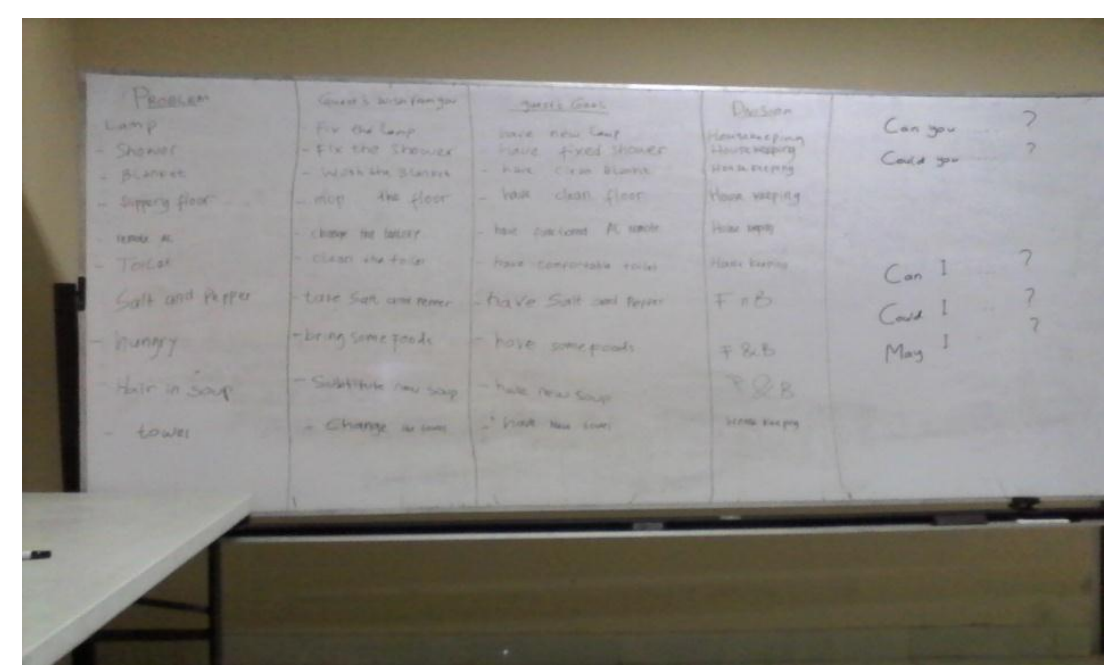

Gb 1. Penyajian Tabel untuk Memberi Pemahaman Awal

Tabel yang disediakan harus bisa menunjukkan aspek apa saja yang sedang dipertukarkan, siapa saja yang terlibat, dan dalam konteks apa. Tabel tersebut diisi oleh para staf sendiri dengan pengetahuan yang dimilikinya, karena mereka memiliki peran masingmasing untuk mengatasi berbagai masalah terkait dengan divisi kerja mereka. Gambar di atas diperjelas menjadi tabel di bawah ini.

\begin{tabular}{|l|l|l|l|}
\hline \multicolumn{1}{|c|}{ Problem } & \multicolumn{1}{|c|}{$\begin{array}{c}\text { Guest's Wish } \\
\text { From You }\end{array}$} & \multicolumn{1}{c|}{ Guest's goal } & \multicolumn{1}{c|}{ Division } \\
\hline Lamp & Fix the lamp & Have new lamp & Housekeeping \\
\hline Shower & Fix the shower & Have fixed shower & Housekeeping \\
\hline Blanket & Wash the blanket & Have clean blanket & Housekeeping \\
\hline Slippery floor & Mop the floor & Have clean floor & Housekeeping \\
\hline AC remote & Change the battery & $\begin{array}{l}\text { Have functioned AC } \\
\text { remote }\end{array}$ & Housekeeping \\
\hline Toilet & Clean the toilet & $\begin{array}{l}\text { Have comfortable } \\
\text { toilet }\end{array}$ & Housekeeping \\
\hline Salt and Pepper & $\begin{array}{l}\text { Take salt and } \\
\text { pepper }\end{array}$ & $\begin{array}{l}\text { Have salt and } \\
\text { pepper }\end{array}$ & Food \& Beverage \\
\hline Hungry & Bring some foods & Have some foods & Food \& Beverage \\
\hline Hair in Soup & Substitute new & Have new soup & Food \& Beverage \\
\hline Towel & Change the towel & Have new towel & Housekeeping \\
\hline
\end{tabular}


Terdapat empat aspek yang perlu diketahui dalam menghadapi permintaan, yaitu masalah (problem), harapan tamu dari anda (guest's wish from you), tujuan tamu (guest's goal), dan divisi (division) yang menangani. Identifikasi masalah bertujuan untuk memahami konteks. Harapan dan tujuan tamu menunjukkan makna pertukaran yang terjadi. Divisi menunjukkan kepada siapa tuturan akan ditujukan.

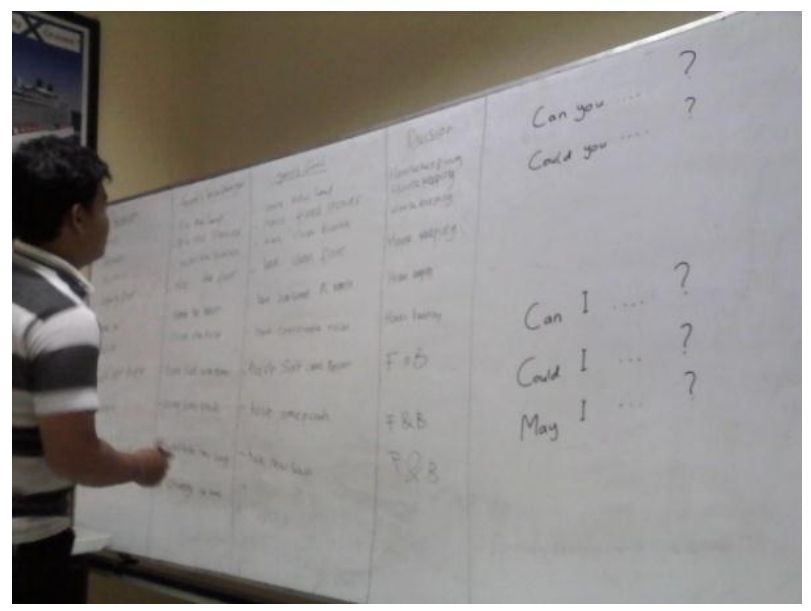

Gb 2. Staf mengisi sendiri tabel yang disajikan

Harapan tamu menempatkan staf sebagai pusat dari melakukan sesuatu. Sebaliknya, tujuan tamu itu menitikberatkan pada tamu itu sendiri untuk menerima sesuatu dari pelayanan staf. Makna transaksional berupa proposal ini akan tampak pada klausa interogatif yang termodulasi untuk mengekspresikan permintaan.

(1) Could you mop the floor?

(2) May I have clean floor?

Tampak pada kedua klausa di atas menunjukkan bahwa klausa (1) berorientasi pada staf untuk memberikan jasa, dan klausa (2) pada tamu untuk menerima jasa. Keduanya berada pada konteks permasalahan yang sama. Yang membedakannya adalah fokus pada siapa, didukung dengan penggunaan kata ganti orang yang berbeda. Martin, Painter, Matthiessen (2003: 62) mengatakan bahwa subjek merupakan elemen yang dapat dinegoisasikan. Ketika tamu mengucapkan klausa (1), kata ganti orang kedua 'you' merujuk kepada staf. Sedangkan, klausa (2) menggunakan ' $I$ ' untuk menunjuk dirinya, tamu itu sendiri

Peserta harus mengerti tentang konsep pertukaran yang terjadi dengan subjek yang sedang dinegoisasikan. Klausa interogatif termodulasi pada struktur mood seperti can you ...? atau could you...? Menunjukkan harapan tamu dari pelayanan mereka. Sedangkan, can I...?, 
could I ...?, atau may $I . . . ?$ menunjukkan tujuan tamu untuk menerima sesuatu dari jasa yang diberikan (lihat klausa interogatif termodulasi pada Eggins, 2005: 69-102). Dengan seperti ini, mereka hanya perlu memahami residue-nya. Hasilnya, dapat diformulasikan seperti berikut ini.

$$
\begin{gathered}
\text { Can/could you guest's wish from you ? } \\
\text { Can/could/may I guest's goal? }
\end{gathered}
$$

Residue menunjukkan hal apa yang sedang dinegoisasikan, apakan guest's wish atau guest's goal. Formula tersebut membantu para staf untuk bisa memahami konsep request sebagai bentuk pertukaran proposal yang ditujukan kepadanya. Jadi, mereka akan langsung memahami adanya permintaan dari tamu bila mereka mendengar ekspresi dengan struktur mood di atas.

Pemahaman ini tentu tidak hanya terbatas pada apa yang dikatakan tamu saja, tetapi juga sikap staf untuk merespon permintaan tersebut. Para staf harus dapat menunjukkan kesediaan mereka untuk memberikan pelayanan. Dalam pandangan LSF, respon yang diberikan dari sebuah permintaan diekspresikan melalui inklinasi. Klausa inklinasi juga termasuk proposal, karena menunjukkan kesungguhan hati untuk memberikan barang atau jasa. Thompson (2004: 67) menjelaskan bahwa inklinasi menunjukkan kemampuan, kesediaan, atau kemantapan hati untuk memenuhi permintaan.

Modulasi juga dapat diungkapkan untuk memberi respon pada klausa inklinasi. Halliday (1990: 86) menjelaskan bahwa modulasi pada inklinasi dapat diekspresikan dengan dua cara, yaitu dengan finite modal dan perluasan predikator. Contoh penggunaan modulasi pada finite modal seperti berikut ini.

(3) Guest : "Can you fix the lamp?"

HK : "Yes, sir. I will take care of that"

(4) Guest : "May I have salt and pepper?"

FB : "Certainly, ma'am. I will be right back with that item"

Perluasan predikator juga dapat digunakan. Contohnya adalah ketika staf tidak dapat menyelesaikan masalah secara langsung seketika, seperti yang tampak pada percakapan berikut.

(5) Guest : "Can you move that picture above my bed?"

HK : "I'm not sure, sir. But let me talk to my supervisor."

(6) Guest : "Instead of herbal tea, could you provide Earl Grey?" 
FB : "I'm sorry, ma'am, but the herbal tea is all we have at the moment

Setelah memahami tahap ini, para staf diharapkan mampu dengan lancar menghadapi berbagai permintaan tamu. Sebagai latihan, mereka melakukan simulasi percakapan antara tamu dan staf dengan menggunakan materi yang telah dipelajari tersebut.

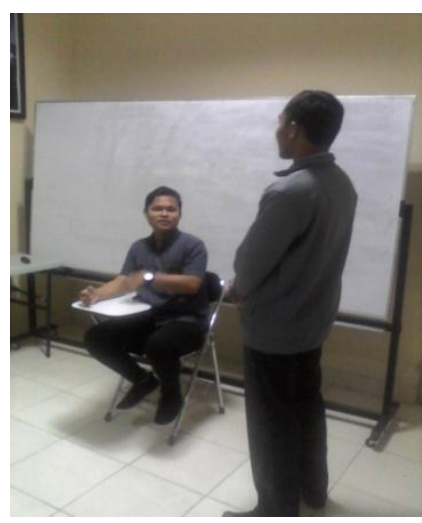

Gb 3. Latihan dengan Simulasi Percakapan

Penjelasan di atas menunjukkan bahwa pendekatan LSF dapat diaplikasikan pada pembelajaran untuk kebutuhan staf. Konsep proposal sebagai bentuk transaksi barang dan jasa sejalan dengan bentuk pelayanan staf HK dan FB kepada tamu hotel.

\section{KESIMPULAN}

Hasil temuan tersebut menunjukkan bahwa konsep transaksi proposal dalam LSF sejalan dalam aplikasinya dengan aktifitas yang dilakukan oleh staf HK dan FB ketika melayani tamu hotel, begitu juga sebaliknya. Aktifitas tersebut adalah memberikan barang atau jasa yang diminta oleh tamu. Bagi tamu, mereka meminta barang atau jasa.

Pemahaman konsep proposal untuk aktifitas berbahasa diperlukan oleh staf agar mereka mengetahui bahwa berbagai perkataan yang mereka dengar dan ucapkan sebenarnya merupakan penerapan bahasa dalam suatu konteks. Tabel dengan kolom guest's wish from you dan guest goal dengan finite dan subjek pada klausa interogatif termodulasi adalah bentuk usaha untuk mengidentifikasi hal-hal apa saja yang dipertukarkan. Hal ini juga termasuk kepada siapa seorang penutur menegosiasikan proposalnya.

LSF memiliki banyak sumber daya yang dapat diaplikasikan pada berbagai kebutuhan, salah satunya adalah untuk pembelajaran bahasa. Sifatnya yang fungsional membuat peserta didik dapat mengetahui bahwa bahasa tidak hanya terbatas pada tata bahasa atau formula semata yang harus diucapkan, tetapi bagaimana bahasa itu diucapkan sesuai dengan fungsinya yang terikat dengan latar belakang konteks. Masih banyak hal yang dapat 
dikembangkan dalam pembelajaran bahasa dengan LSF. Temuan dalam penerapan pembelajaran ini berusaha memberikan kontribusi untuk pengajaran bahasa kepada peserta didik sebagai bentuk komitmen profesionalitas mereka, khususnya mereka yang terikat dengan profesi tertentu seperti untuk staf HK dan FB ini. Dalam perkembangannya, strategi pengajaran dengan LSF ini dapat diterapkan untuk sekolah, pelatihan, dan kampus.

\section{DAFTAR PUSTAKA}

Blaxter, L. Hugher ; dan Thight, M. (2006). How to Research. Buckingham: Open University Press.

Djatmika. (2012). Perilaku Bahasa - Di Dalam Teks Kontrak Dari Kaca Mata Linguistik Sistemik Fungsional. Surakarta: UNS Press.

Eggins, Suzanne. (2004). An Introduction to Systemic Functional Linguistics. London: Continuum.

Halliday, M.A.K. (1990). An Introduction to Functional Grammar. London: Arnold.

Halliday, M.A.K; dan Hasan, Ruqaiya. (1986). Language, Context, and Text: Aspects of Language in a Social-Semiotic Perspective. Victoria: Deakin University.

Martin, J.R; Matthiessen, Christian M.I.M; dan Painter, Claire. (2003). Working With Functional Grammar. London: Arnold

Spradley, J.P. (1980). Metode Etnografi (M.Z. Elizabeth, Terjemahan.). Yogyakarta: Tiara Wacana.

Sudaryanto. (1990). Aneka Konsep Kedataan Lingual dalam Linguistik. Yogyakarta: Duta Wacana University Press.

Sutopo, H.B. (2006). Metodologi Penelitian Kualitatif - Dasar Teori dan Penerapannya dalam Penelitian. Surakarta: Universitas Sebelas Maret.

Thompson, Geoff. (2004). Introducing Functional Grammar (2 ${ }^{\text {nd }}$ Edition). London: Arnold

Zwier, Lawrence J. \& Caplan, Nigel. (2007). Everyday English for Hospitality Professionals. Michigan: Compass Publishing. 